\title{
The Performance of Health Workers
}

\section{Kwesi Asabir, Sophie Witter, Christopher H. Herbst, and Kwesi McDamien Dedzo}

This chapter examines the performance of health workers in Ghana, distinguishing and reviewing evidence related to two types of performance issues: (1) health workers who do not possess the necessary skills, knowledge, or means to carry out their jobs sufficiently (they are not competent or able to provide services) - a situation often linked to the lack of necessary education and training or to difficult working environments; and (2) health workers who do not sufficiently or ethically apply themselves, their knowledge, or their skills (they are absent, unresponsive, unproductive, and engage in questionable behavior)—a situation often linked to a lack of motivation or lack of accountability arrangements.

\section{Summary of Findings}

Evidence on health worker performance is extremely limited in Ghana. Some of the evidence on health worker competencies suggests failures in good practice, although these failures are confined to specific services-in particular, antenatal care and intrapartum health services. Most healthtraining institutions are accredited, though standards of accreditation vary. The quality of health worker training in Ghana, although generally considered high, is constrained by physical and technical capacity weaknesses, especially in schools outside of greater Accra. Access to in-service 
training is perceived as insufficient and unfair, and evidence of the effectiveness of in-service training is lacking. Health workers also often lack adequate equipment and supplies needed to perform their jobs effectively, and the perception of working long hours (especially if on-duty hours are considered) and having fairly high (but not unreasonable) case loads add to a challenging work environment.

The extent to which health workers apply themselves to deliver services is mixed. Absenteeism does occur, particularly in urban areas, and is largely linked to moonlighting and dual practice. Customer satisfaction surveys generally yield high scores with regard to health worker responsiveness, although the results are not consistent with the poor attitudes of health workers reported in qualitative research. Health worker productivity varies by facility, cadre, and region, and dishonest practices seem to be limited by controls over collecting payments and managing drugs at the facility level.

Management practices (or the lack thereof) appear to strongly affect the extent to which health workers apply themselves to delivering services. Management capacities and the associated quality of performance management vary significantly in Ghana. The central Ministry of Health level seems unable to adequately carry out performance management functions at the decentralized level. Important management authority to hold health workers accountable for their performance is not decentralized to the facility level. A culture of automatic promotion, based on seniority and with no sanctions for poor performance and no rewards for good performance, is a problem. Finally, one study on some of the factors that most motivate health workers indicates the importance of intrinsic factors.

\section{Evidence on Health Worker Performance}

Evidence pertaining to two different dimensions of health worker performance is reviewed below: (1) the extent to which health workers are competent and able to deliver health services and (2) the extent to which health workers apply effort to delivering health services.

\section{Competence and Ability to Perform}

Globally, health worker competence and ability to deliver services of acceptable quality can be assessed by a number of different methods, including vignettes, clinical audits, patient surveys, provider observation, confidential enquiries, and analysis of case mortality rates. In Ghana, the 
number of such studies is low, and their scope is limited to looking at specific service areas, such as antenatal care. The existing studies do reveal some concerns, although much more comprehensive and more recent evidence will be needed to draw wider conclusions about the competence and ability of health workers to provide services in Ghana.

A quality-of-care assessment undertaken in 2002 by the Ghana Health Service found that the performance of antenatal care services, including routine history taking, lacked comprehensiveness. ${ }^{1}$ In some cases, patients were not asked routine questions, such as their age or the date of their last menstrual period; diagnosis of signs, symptoms, and risk was also deemed inadequate. Caregivers rarely screened patients for sexually transmitted diseases or offered prophylaxis, and discussions on the progress of pregnancy and delivery plans were observed in only a third of patient-provider interactions (GSS, Ministry of Health, and ORC Macro 2003).

Findings from a 2003 study comparing key performance indicators related to antenatal care services in control clinics with clinics where a World Health Organization (WHO)-focused antenatal care package had been introduced indicate that performance scores for all clinics remain well below maximum possible scores. This gap suggests widespread deficiencies in the technical quality of care (Nyarko et al. 2006).

A 2007 maternal health survey also found gaps in care: only 37 percent of women were given intestinal parasite drugs during antenatal care visits, 68 percent were informed of where to go in the event of complication, and 70 percent were informed of the signs of birth complications (GSS, GHS, and Macro International 2009). ${ }^{2}$ Just under two-thirds of women received at least two tetanus typhoid injections. These indicators show improvement from a 2003 survey, despite falling short of full coverage.

More recent studies, of the quality of care of intrapartum health services, also reveal deficiencies. A 2006 study surveying 9 percent of deliveries in 49 facilities (22 in the Central Region and 27 in the Volta Region) found that the quality of clinical medical care was substandard in both regions (averaging 14-15 out of a possible 44 points for management of all stages of labor). The lowest scores were for first-stage labor monitoring with a partograph, ${ }^{3}$ and for immediate postpartum monitoring of mother and baby. Quality-of-care scores were lower in private facilities than in public ones, and they were higher in facilities in which the use of such tools was higher (Deganus and Tornui 2006).

A related study in 2006 of the quality of maternal care in 14 regional and district hospitals in the Central and Volta regions also found evidence of poor practice: partographs were used in only a third of cases, 
fetal heart rates were not routinely recorded, and magnesium sulfate was used in fewer than half of cases of hypertensive diseases for which it was indicated (Townend et al. 2006). The delay between the recognition of a complication and the patient being taken to the operating theater for a caesarean was substantial, exceeding the 30-45 minutes recommended.

\section{Application of Effort}

The extent to which health workers sufficiently apply themselves to their tasks and functions of serving patients in their respective place of employment is reflected in health worker (1) availability/absenteeism, (2) responsiveness, (3) productivity, and (4) professional probity. The following discusses evidence pertaining to each of these aspects.

Availability. Globally, several indicators (staffing ratios, the number of vacant posts, staff turnover, the distribution of health workers, staff attendance/absenteeism, and waiting times) can be used to assess availability. The distribution of health workers was discussed in chapter 3 , which shows health workers to be much more available in urban than rural areas. The focus in this section is on the limited findings of largely qualitative evidence on staff attendance and waiting times for patients. Ghana has no quantitative data on attendance/absenteeism.

Existing qualitative evidence suggests that absenteeism is not very frequent, and that it is more common among some cadres than others. When it does occur, medical officers are more likely to be absent from work than professional nurses, who in turn are more likely to be absent than auxiliary support staff (Lievens et al. 2011). Engagement in dual practice, or moonlighting - especially of higher-level cadres-is the main cause of absenteeism. Interestingly (in light of the perception of infrequent absenteeism), moonlighting is perceived to be fairly common among health workers in urban areas. More stringent legislation making moonlighting illegal, as well as the practice of covering for absent colleagues, may play a role in minimizing absenteeism and its negative effects (box 4.1).

Reports on waiting times for patients to see health workers are mixed. In 2002, 74 percent of patients reported that waiting times were average to excellent (Awases et al. 2004). A 2006 WHO study revealed that 62 percent of patients in intervention clinics were satisfied with waiting times for antenatal care (Nyarko et al. 2006). In a 2009 maternal mortality survey of women who did not deliver in a health facility (46 percent), 


\section{Box 4.1}

\section{Dual Practice and Moonlighting}

Dual practice and moonlighting refer to health workers who are engaged in a second job during or after regular working hours. For the public sector worker, this often involves working in the private sector (own practice or private employer). Globally, some observers believe that dual practice or moonlighting adversely affects health worker performance: it is a major cause of absenteeism (in the public sector), and because health workers "juggle more than they can handle," it can negatively affect their responsiveness and productivity. Others argue that, for some cadres, dual practice may actually improve performance, especially if health workers practicing in the private sector bring new knowledge and skills back to the public sector (Ferrinho et al. 2004).

Qualitative evidence suggests that dual practice is fairly common among some health workers in Ghana and may negatively impact their performance. Focus group discussions found that opportunities for dual practice are more common in urban than rural areas, and that public sector health workers, especially doctors and nurses, commonly engage in private practice. This is perceived to be problematic: focus group discussions reveal perceptions that two jobs can be exhausting, leading to lower efficiency and less-positive attitudes toward patients. Some health workers in Ghana scale down their (primary) clinical public work to provide better services to their (secondary) professional private activities (Lievens et al. 2011).

As for absenteeism, health workers refer to the practice of setting up systems so that absenteeism is minimized. Factors reportedly constraining absenteeism include the need for staff on one shift to wait for their replacements to arrive before they can leave (thus exerting pressure on colleagues to arrive on time). In a well-staffed public facility, health workers often set up an informal scheduling system so that each worker works in rotation with a colleague who covers for his or her absence (Lievens et al. 2011). Nurses arriving late sometimes have to pay their colleagues for covering for them. In addition, the lack of good private employment opportunities and the understaffing of facilities in rural areas limit both the temptation and the ability to shirk duties at public institutions (Lievens et al. 2011).

The reforms linked to the salary rationalization program, moreover, may have made dual practice more difficult. Under the new terms of employment, staff are not permitted to engage in private practice, but enforcement is weak (Lievens 


\section{Box 4.1 (continued)}

et al. 2011). A study after the salary rationalization program came into effect finds that only 1 percent of health workers (two doctors) reported any income from private practice (Witter, Kusi, and Aikins 2007). Because the study was carried out in rural areas and was based on self-assessment, however, it might not be representative of the actual picture throughout the country.

10 percent mentioned service-related problems, with inconvenient service hours ( 8 percent) foremost of the problems (GSS, GHS, and Macro International 2009). Other service-related problems cited include long waiting times and the lack of a female doctor. In a mystery-shopper exercise, ${ }^{4}$ conducted in the outpatient departments of 12 hospitals and polyclinics in Greater Accra, waiting times for patients to see a medical provider were two to five hours, though this might not be typical of other areas (Bannerman et al. 2010). Several factors other than provider availability—including demand for services, staffing norms, and service organization-affect waiting times, which are thus only a weak indicator of staff availability.

Responsiveness. The responsiveness of the provider to the patienttreating people decently, regardless of who they are or whether their health improves (WHO 2006) — is usually assessed through patient surveys or qualitative research, including focus group discussions. Some such evidence exists for Ghana, although it is not entirely reliable because it tends to reflect expectations and cultural factors.

Existing evidence from the mid-2000s suggests that patient satisfaction with care in Ghana was generally high. Several surveys conducted in the mid-2000s show that patients were generally satisfied with the respect, attention, communication, and services provided by health workers. More than 75 percent of respondents in another study rated the quality of care as average to excellent on most parameters (Awases et al. 2004). And 93 percent of respondents rated "respect given to patients" and "communication between health workers and patients" as average to excellent, while 82 percent rated "attention given to patients" similarly. In a separate study, most patients reported being satisfied with the antenatal care services they received (Nyarko et al. 2006). 
More recent studies on the attitudes and behavior of health workers are mixed. Focus group discussions reveal that attitudes toward health workers are best in Christian Health Association of Ghana facilities and are better in rural facilities than in urban ones. Evidence from the private sector is mixed, with some users reporting better treatment than in the public sectors and some worse. There are no indications that patients with HIV/AIDS are sidelined or treated differently, despite health worker fears of contracting the disease (box 4.2). Some patients indicate that health workers became impatient and angry when patients failed to comply with treatment (for diseases in general), shouting at and insulting them; others report rude behavior, such as staff chatting with friends or spending too long on the phone. They also reported that the higher use associated with the National Health Insurance Scheme increased tensions between providers and patients (Lievens et al. 2011).

A recent mystery-shopper exercise in Accra reported overall positive findings of health worker behavior, with only some select instances raising concern (Bannerman et al. 2010). Overall, many respondents in the exercise indicated that staff were polite, friendly, welcoming, courteous, and proactive and maintained good eye contact. But some respondents reported staff chatting to colleagues while interviewing patients and attending to their own affairs-for example, selling secondhand

\section{Box 4.2}

\section{Health Worker Responsiveness toward Patients with HIV/AIDS}

About half of all health workers in Ghana worry that they may contract HIV through a work-related injury, and 38 percent report stress from caring for HIVpositive patients. Despite this, there is no evidence that Ghanaian health workers treat HIV/AIDS patients differently than they treat other patients; nor do they opt out of clinical jobs (Lievens et al. 2011). Focus group discussions reveal that health workers are happy to use their professional skills in treating and caring for people with HIV (Lievens et al. 2011). An earlier study, conducted in 2002, found that 93 percent of health workers in Ghana were willing to work with HIV patients. This level of willingness is higher than in some other African countries. In Zimbabwe, for example, where the prevalence of HIV/AIDS is much higher than in Ghana, only 76 percent of surveyed health workers were willing to care for or treat people with HIV (Awases et al. 2004). 
clothing - rather than dealing with patients. Others reported rudeness, coldness, shouting, unresponsiveness, and irritation when asked questions, and an overall lack of respect.

One perceived problem in Ghana is that patients have few avenues for expressing their views on treatment standards to management. In focus group discussions, users of public facilities suggest that complaint procedures do not exist or are not well publicized (Lievens 2011). Mystery shoppers in Accra report that there were complaint desks in most of the facilities, but the desks were not staffed and often lacked complaint forms and pens. Most staff also lacked name tags, making it difficult to report individual staff for poor behavior (Bannerman et al. 2010). Initiatives such as patient charters and quality assurance are being introduced to address this issue, but it is too early to assess their effectiveness in changing organizational culture.

Productivity. WHO defines productivity as "producing the maximum effective health services and health outcomes possible given the existing stock of health workers" (WHO 2006, p. 68). Different methodologies can be used to assess health worker productivity, but varying case mix and quality of care complicate assessment. In Ghana, the two broad measures of workforce productivity used in several studies were equivalent patient days per health worker, for both skilled and unskilled workers; ${ }^{5}$ and total salary cost per equivalent patient day. ${ }^{6}$ More information on the methodology used to assess productivity (and its limitations) can be found in (Vujicic, Addai, and Bosomprah 2009).

The results from two productivity-mapping exercises in Ghana (one in 2004 and one in 2007) using these broad measures of productivity reveal a wide variation in workforce productivity across districts and regions. The 2004 study found that, on average, productivity in Ghana was comparable with countries such as Sri Lanka, but that there were wide differences across facilities, with the highest productivity observed in faith-based hospitals (Adams, Darko, and Accorsi 2004). Facilities in the north showed the lowest cost per patient day equivalent $(\notin 73,275$, or Ghanaian cedis) (Adams, Darko, and Accorsi 2004).The authors attributed the higher productivity to the lower staffing ratios and the greater use of mission facilities. In the public sector, regional hospitals were less efficient than district hospitals. According to a 2007 study, the district-weighted national average workforce productivity level was 315 equivalent patient days per health worker and $₫ 51,284$ per equivalent patient day (Addai 
and Bosomprah 2007). Productivity levels were highest in the Ashanti, Brong Ahafo, and Central regions and lowest in Greater Accra (figure 4.1).

Professional probity. In addition to being available, responsive, and productive, it is important that health workers behave ethically toward their employer and patients, both medically and financially. Health workers must not take advantage of their professional knowledge and patients' vulnerability for gain, and they must not steal funds, drugs, or other supplies from the facilities where they work. Qualitative evidence on professional probity indicates that such behavior may be fairly limited in Ghana, although more research will be needed to draw more concrete conclusions.

Focus groups reveal that charging informal fees does occur in some instances, but is not very common. Sometimes patients give a token of gratitude to staff, but they do so on their own initiative (Lievens et al. 2011). When these do occur, such payments are often higher in urban areas than in rural and possibly periurban areas.

The theft of funds by health workers is usually perceived to be constrained by administrative systems that restrict financial transactions to

\section{Figure 4.1 Productivity of Health Workers by Region, 2007}

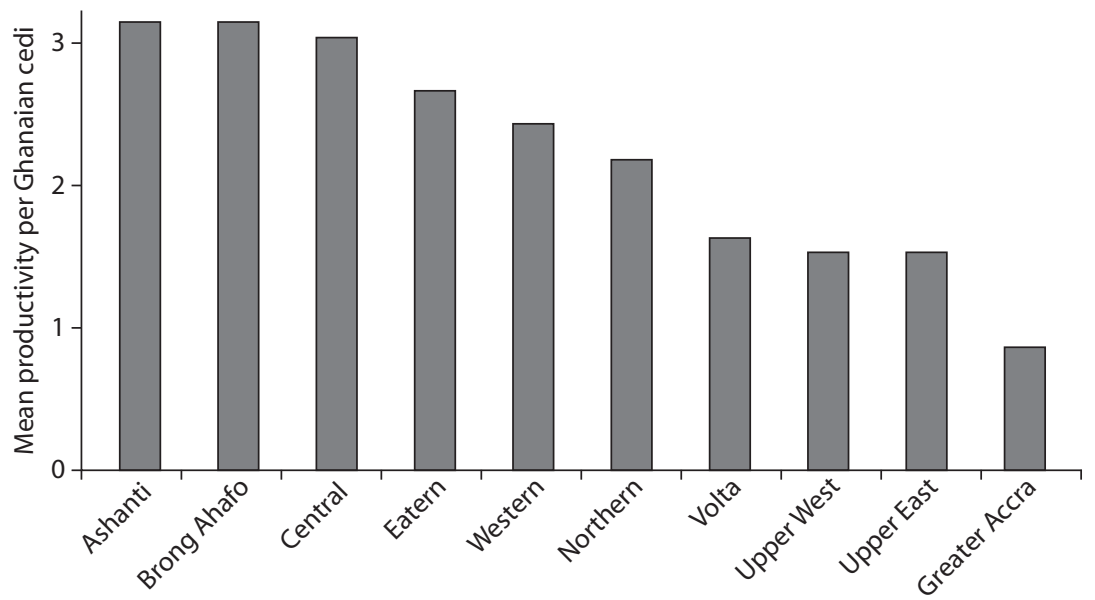

Source: Addai and Bosomprah 2007.

Note: These findings should be interpreted with caution. They make four assumptions: (1) case-mix variation is negligible or the same across facilities; (2) staff absenteeism is negligible or the same across facilities, (3) all facilities are fully functional (there are adequate equipment, staff, and drugs), and (4) all facilities have similar catchment areas. 
accountants, though sometimes health care staff collude with administrators to commit fraud (Lievens et al. 2011). A mystery-shopper exercise in Greater Accra did find some instances of charges that were not properly invoiced, charges levied for jumping the queue, and charges that were allowed to go unpaid if the patient could not pay (Bannerman et al. 2010). But such instances are not common (Lievens et al. 2011).

Focus group discussions reveal that incidents of drug pilfering are relatively uncommon. When it does occur, such pilfering is more common in rural than urban areas (Lievens et al. 2011). Facilities have several curbs on drug pilfering. Pharmacies use drug sheets to keep track of quantities and prices, and pharmacists and drug administrators are the only staff with direct access to pharmaceutical stocks. Only physicians and some nurses can prescribe medicine, further limiting potential pilfering. If caught, a health worker might be dismissed. But some pharmacists are reportedly lenient when providing drugs to health workers, and it is not uncommon for health workers to obtain drugs without prescription for themselves and their family members (Lievens et al. 2011).

The practice of providing informal care, such as free medical advice given to friends and family in nonclinical settings, is widespread and sometimes deemed to be rooted in Ghanaian culture. Patients regard a refusal to provide such care as rude, and it is potentially harmful to the provider's reputation. As a result, doctors tend to accept informal requests, though an increased awareness of liability issues seems to have led more doctors and practitioners to refer patients to hospitals (Lievens et al. 2011).

\section{Determinants of Performance}

We review below the factors that determine the different dimensions of performance: (1) the factors impacting competence and ability and (2) the factors impacting application of effort. Such evidence may not only help explain the above findings on performance, but may also indicate the extent to which these performance dimensions may be further compromised.

\section{Factors Impacting Competence and Ability}

The extent to which health workers are sufficiently competent to carry out their service delivery functions is largely determined by the accessibility, quality, and relevance of their education and training. The 
extent to which health workers are sufficiently able to carry out services, on the other hand, is largely determined by the availability of supportive working environments (manageable workloads, availability of equipment and supplies, and so on).

Education and training. Although the overall quality of secondaryschool graduates entering health-training institutions is perceived to be high, there are indications of some regional variations, with the quality of admitted students in the south perceived to be higher than in the north. Focus group discussions reveal that, because more students want to enter training institutions in the south-especially the Korle $\mathrm{Bu}$ Teaching Hospital in Accra-and because entrance is strictly based on secondary-school grades, the better students end up in the south (Lievens et al. 2011).

There are concerns that the quality of education is uneven across institutions, particularly at the training institutions of mid- and lower-level cadres (Beciu et al. 2009). Concerns about quality are largely attributed to a shortage of teachers and their lack of adequate clinical experience, a lack of access to up-to-date information sources, a lack of systematic and reliable internal mechanisms for revising the curriculum, an excessive emphasis on theory at the expense of practice, an insufficient number of accredited teaching facilities, and the lack of preparedness of high-school graduates to handle science and preclinical training. Appendix B discusses in detail the physical, technical, and organizational capacity challenges of many health-training institutions in Ghana. Schools outside greater Accra are particularly disadvantaged (Beciu et al. 2009).

In a 2009 study by Beciu et al., the heads of several health-training institutions were asked to identify key internal and external threats to their performance as a pedagogical institution. Lack of adequate funding, pressures to raise enrollment without parallel increases in staff and physical infrastructure, poor qualification of staff, and low workplace ethics and morale were among frequently cited challenges (box 4.3). Moreover, the study found that 20 percent of the surveyed health-training institutions in Ghana were not accredited by the National Accreditation Board (Beciu et al. 2009).

Challenges linked to in-service training are also reported. In focus group discussions, some health workers felt that access to in-service training opportunities is inadequate and that, as a result, critical skills and competencies-including those related to antenatal care-were underdeveloped or outdated. Workshop opportunities sometimes cannot be pursued 


\section{Box 4.3}

\section{Internal and External Threats as Perceived by the Heads of Schools, 2008-09}

\section{Medical and dental schools}

- Cumbersome administrative policies that need updating

- Poor work ethics

- Competition with other schools for resources

- Pressure to increase student numbers without a commensurate increase in funding

- Low funding from donor agencies thanks to the global financial crisis

\section{Health sciences schools}

- Lack of motivation for teachers

- Lack of transportation

- Inadequate storage facilities

- Lack of administrative staff

- Inefficient finance officer

- Pressure on school to enroll more than it can handle

\section{Nursing and midwifery schools}

- Lack of water, electricity, and toilet facilities

- Low qualification of staff

- High teacher turnover rates

- Few mental health tutors

- Inadequate midwifery tutors

- Intense pressure on admissions (political interference)

\section{Community health and health assistant training schools}

- Lack of accommodation and lack of access to electronic media

- Inability to pay casual or part-time tutors

- Political interference and pressure for admissions

Source: Beciu et al. 2009.

because health facilities lack enough personnel to cover shifts that would allow health workers to participate or because fees are too high. Professional nursing associations try to facilitate access to continued education, but doing this sometimes conflicts with the interests of employers (Lievens 
et al. 2011). There is consensus that the allocation process for in-service training (that is, determining who can receive training) is nontransparent.

Little information is available regarding the effectiveness and quality of in-service training. Some observers note the need for more integrated training (rather than courses on specific programs), more flexibility in the type of cadres trained, more applied teaching methods (such as on-thejob training, with observation of performance, peer review, and periodic feedback), and a proactive approach to training based on district needs rather than availability of funding (Agyepong 1999).

Working environment. Many health workers in Ghana perceive workload to be excessive. A heavy workload can increase productivity, but it poses risks to the quality of care. Focus group discussions reveal that most health workers believe that heavy workloads reduce the time doctors and nurses can spend with each patient, leave no time for lunch or other breaks, and lead to complaints from patients about the lack of dedication of health staff (Lievens et al. 2011).

A 2008 study of workloads in the Eastern Region found that, on average, doctors see 45 patients a day and perform four operations a week. The average number of patients a day was 65 for medical assistants. Midwives performed just three deliveries a week (Addo 2009). In a 2005 study of the Central and Volta regions, the self-reported average number of patients seen a week was 269 for doctors, 172 for medical assistants, 119 for public sector midwives, 103 for community health nurses, 86 for nurses, and 38 for private midwives (Witter et al. 2006).

Workloads for public midwives were highest in regional hospitals and health centers and lowest in faith-based hospitals (figure 4.2) (Witter, Kusi, and Aikins 2007). Although there are no set international (or Ghanaian) norms for workloads, Ghana's health staff might not be considered overworked compared with the norm of 100-245 patients a week in South Africa (Kraus 1998).

Self-reported working hours for some cadres are extremely high. A 2005 survey of public and private health workers reported an average of 54 hours a week for community health nurses, 109 hours a week for doctors, and 129 hours a week for medical assistants (Witter, Kusi, and Aikins 2007). These levels are self-reported and include on-call time, but it is clear that globally, some cadres are on duty for very long periods. Doctors in the United States, for example, report working 51 hours per week (USA Today, 2010).

Many factors contribute to these workloads. In the past, attrition from retirement and outmigration may have resulted in excessive workloads 
Figure 4.2 Mean Daily Workload per Public Midwife by Facility Type, 2007

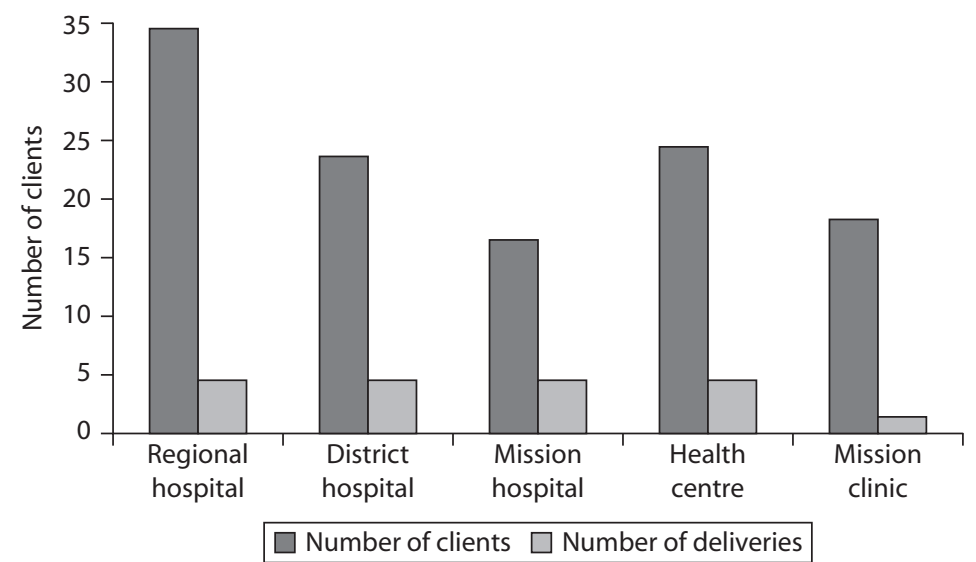

Source: Witter, Kusi, and Aikins 2007.

for health workers who remained in Ghana (Awases et al. 2004). As described in chapter 2, however, attrition is no longer the problem it once was. Focus group discussions in 2007 revealed that most recent extra work may be the result of requirements of the National Health Insurance Scheme (see CSR-Health Ghana 2011 for more detail on that scheme).

Quality of care is influenced not only by provider competencies, but also by the enabling environment in which health workers operate. A 2002 study of the quality of antenatal care found that only half of antenatal care facilities had essential equipment and supplies, and just 6 percent were fully equipped to manage complications of pregnancies (GSS, Ministry of Health, and ORC Macro 2003). Tests for anemia were available in only 57 percent of facilities, and tests for protein deficiencies in only 62 percent. Only 36 percent of facilities had essential items needed to offer high-quality counseling, 24 percent had essential items to prevent infections, and 11 percent had all essential items for a good physical examination.

A service provision assessment survey conducted in 2005 (Quality Health Partners and Ghana Health Service 2005) found that only 61 percent of facilities offering antenatal care had the required infectionprevention items, 60 percent had basic medicines and equipment for a normal delivery, and just 34 percent had all delivery room infrastructure and furnishings. This study concluded that only 40 percent of health centers had transportation procedures in place for women with obstetric 
emergencies. More generally, facility infrastructure was found to be lacking: only 13 percent of facilities (41 percent of hospitals) had regular infrastructure support (electricity, water, communications); 38 percent had regular, 24-hour supply of electricity or a generator; and 35 percent had a source of water available year-round.

A more recent study found the availability of supplies needed for comprehensive emergency obstetric care in some facilities-including blood transfusions, laboratory tests, drugs, equipment, and consumables- to be acceptable (Ansong-Tornui et al. 2007). Using a confidential enquiry technique to examine 20 maternal deaths in hospitals in the Central and Volta regions, the study concluded that care was substandard, particularly for complications and acute emergencies. But it suggested that the quality-of-care failures reflect staff competence and practice rather than the lack of needed facilities.

Work environments marked by an insufficient number of health workers-a condition prevalent particularly in rural areas-has further implications on performance. A synthesis report on six African countries, including Ghana, suggests that the attrition of skilled health professionals from Africa before 2004 might have also reduced the quality of care, because it resulted in lower-level workers performing the functions of the higher-level workers who had left (Awases et al. 2004). Whereas attrition may have improved, dire shortages of human resources for health remain, particularly in rural facilities (see chapter 3 ). Recent focus group discussions with health workers and patients reveal that informal skill substitution continues to occur: ward assistants are performing the jobs of health assistants, and nonpharmacists regularly sell prescription and over-thecounter drugs in both the public and private sectors (Lievens et al. 2011). Patients complained about the quality of care provided by such underqualified staff (Lievens et al. 2011).

\section{Factors Impacting the Application of Effort}

The extent to which health workers apply themselves to provide services (reflected in the picture on availability/absenteeism, responsiveness, productivity, and professional probity) is largely determined by (1) the extent that management and accountability structures are in place to supervise and hold health workers accountable, and (2) the extent to which health workers are motivated to apply themselves and deliver quality services.

Management and accountability structures. An effective management and accountability system is one of the most powerful determinants of 
many aspects of performance. Performance management (a product of such a system) refers to "measuring, monitoring, and enhancing the performance of staff, as a contributor to overall organizational performance" (Martinez and Martineau 2001, p. 1). This includes holding staff accountable for their actions. Productivity, responsiveness, absenteeism, and professional probity are globally directly linked to functioning management systems. In addition, some of the above-discussed performance determinants (for example, the provision of in-service training, the availability of equipment and supplies, and manageable workloads), as well as health worker motivation (discussed below), are often closely linked to effective performance management.

There are some indications that management capacities and the associated quality of performance management varies significantly in Ghana (by region and facility), with significant implications for some key performance variables. Efforts to identify the causes of variations in productivity (figure 4.3), for example, did not result in clear links to expected factors such as skill mix, pay, coverage of services, or density of health workers (World Bank, Ministry of Health, and Ghana Health Service 2006). Such findings, in addition to direct evidence of a correlation between supportive supervision and increased productivity in Ghana (see study by Frimpong et al. 2011), suggests that management and leadership —as a residual category—may be an important component in explaining the variations in absenteeism, responsiveness, productivity, and professional probity. A quality assurance study in the Eastern Region showed that among the four districts consistently leading in a regional league table (ranking) on such performance aspects (see box 4.4), three had the most stable and experienced management teams (Acquah et al. 2008).

Important management authority to hold health workers accountable for their performance (including the responsibility to carry out formal performance appraisals or to fire health workers) is not decentralized to the facility level, although there are variations by sector (see appendix A). A mystery-shopper exercise in Accra noted the absence of serious sanctions for staff who demonstrate abusive behavior-as well as the absence of rewards for staff who deliver good patient care (Bannerman et al. 2010). Many health workers in Ghana deem the centrally managed civil service-wide staff performance appraisal systems to be ineffective for managing performance. Some health workers point to the large number of nonperforming health workers as an illustration of a nonfunctional appraisal system (Lievens et al. 2011). 


\section{Figure 4.3 Productivity of Health Workers as a Function of Pay and Coverage Levels, 2006}

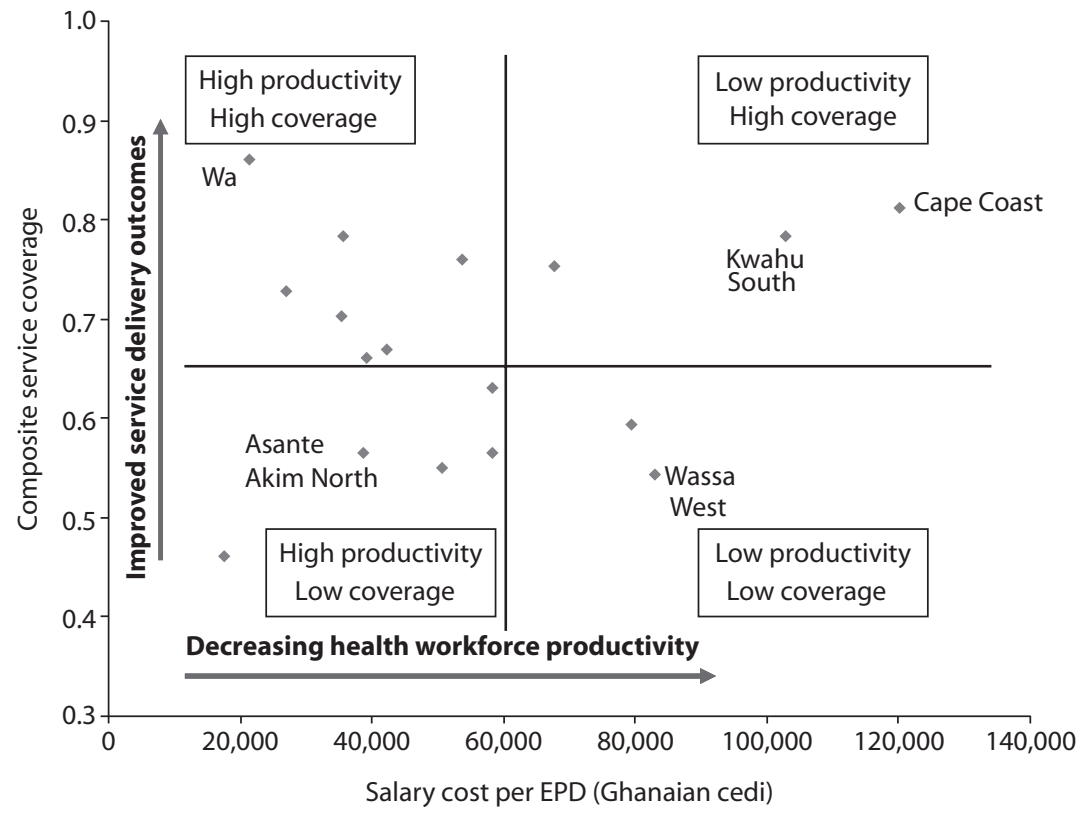

Source:World Bank, Ministry of Health, and Ghana Health Service 2006. Note: $\mathrm{EPD}=$ equivalent patient day.

Despite the absence of more encompassing management decisionmaking authority at the facility level, there is nevertheless some evidence that positive management practices at select health facilities does occur. Focus group discussions with health workers reveal that, when a facility manager or supervisor is committed and dedicated to improving the performance of his team, performance evaluation does occur. Such appraisals consist of a face-to-face meeting between the supervisor and the health worker, using a form that is jointly filled out. Normally the evaluator is the direct manager of the appraised health worker. Both parties express their views, and, in case of disagreement, a panel is called to intervene. After the form is read aloud, both parties sign it (Lievens et al. 2011). There is some evidence that other simple human resource management practices, reflecting the quality, capacity, and dedication of facility managers, are also sometimes applied to great effect (see box 4.4).

Some attempts have been made to strengthen and incentivize management efforts at the district level. Experimentation with using a league 


\section{Box 4.4}

\section{A Positive Hospital Management Experience}

Some staff in select facilities in Ghana are reporting high levels of satisfaction and trust in their management. An evaluation of a well-performing regional hospital in the Central Region identifies some of the human resources management practices that contributed to success. The study concludes that a well-balanced human resources management "bundle" or collection of management policies can stimulate organizational commitment and accountability of health workers, even where managers have narrow decision spaces. The bundle included a clear and well-communicated vision of the role of the hospital, which included elements such as striving for excellence, offering services to all, paying attention to personnel, and practicing sound financial management. Management took staff training seriously and decentralized responsibility where possible. Teamwork, reduction of status differences, and open communication were prioritized. Access to top management was facilitated by an open door policy, and top managers remained engaged in operational issues. The socialization of staff was also important, with both formal inductions and close supervision and mentoring by colleagues. These practices were applied to all cadres. As a result, staff reported feeling recognized and supported — and reported high levels of trust in management.

Source: Summarized from Marchal, Dedzo, and Kegels 2010.

table approach in one region seems to have yielded benefits. This quality assurance approach, tested in the Eastern Region, combines peer review/ qualitative assessment with periodic feedback based on reports and district indicators. A 2008 evaluation concluded that district teams and hospitals found the system motivating. High-scoring districts received citations and some small prizes, and low-scoring districts were encouraged to study high-scoring facilities. Reported positive effects included increased use of monitoring data and improved communication among stakeholder groups. But there were some methodological concerns over whether the scoring was too subjective and allowed for factors outside the scope of health services (Acquah et al. 2008).

Accreditation and regulation of the health sector as a whole, which have often been weak until now, are receiving new impetus from the funding channel of the National Health Insurance Scheme. As a new thirdparty purchaser, the scheme is setting up an accreditation program that 
might have quality-assurance implications for facilities and individuals (Witter and Garshong 2009). The Christian Health Association of Ghana is also developing tools to assess and monitor facility performance. Focus group discussions, moreover, point toward recent improvements in some management controls-for example, health workers do not handle drugs without a prescription or involve themselves in financial transactions-which may have kept corruption and drug pilfering in check (Lievens et al. 2011).

Motivation to perform. The motivation of health workers is a critical determinant of the extent to which health workers apply themselves to the delivery of high-quality services. Health worker motivation is defined as the "willingness to exert and maintain an effort toward organizational goals" (Franco, Bennett, and Kanfer 2002). Generally, factors that motivate health workers tend to vary (by cadre, number, and importance), and can include both altruistic factors, salary, or bonuses, and many of the performance determinants discussed above (that is, opportunities for training, working conditions, performance management, and so on).

Comprehensive evidence of health worker motivation in Ghana does not exist. One survey on motivation that included many lower-level cadres indicated that social status and intrinsic motivation play a powerful role. In a 2006 survey of 374 health workers, which included cadres such as traditional birth assistants in the Central and Volta regions, respondents were asked to rank the factors that motivated them (figure 4.4). The leading factor was the opportunity to serve the community (36 percent of respondents), followed by the social status attached to the profession (20 percent) and the additional allowances paid (14 percent). General working conditions, salary, and allowances, and the opportunity for training were much lower on their list.

Very few other studies shed light on health worker motivation in Ghana, and much more evidence is needed in this regard. In particular, no study has evaluated the effect of increases in health worker salaries on motivation to perform (see appendix $\mathrm{C}$ for information on salary increases). Existing evidence is piecemeal and ad hoc. Focus group discussions in Ghana reveal that appreciation and recognition increase motivation, while bad management and unfair performance appraisals reduce it (Lievens et al. 2011). Anecdotal (nonrepresentative) evidence seems to suggest that some health workers (particularly those who are starting) are frustrated with delays in their salary payments and feel that long delays and the costs involved in getting on the payroll (for example, requiring 
Figure 4.4 Motivating Factors for Health Workers in the Central and Volta Regions, 2006

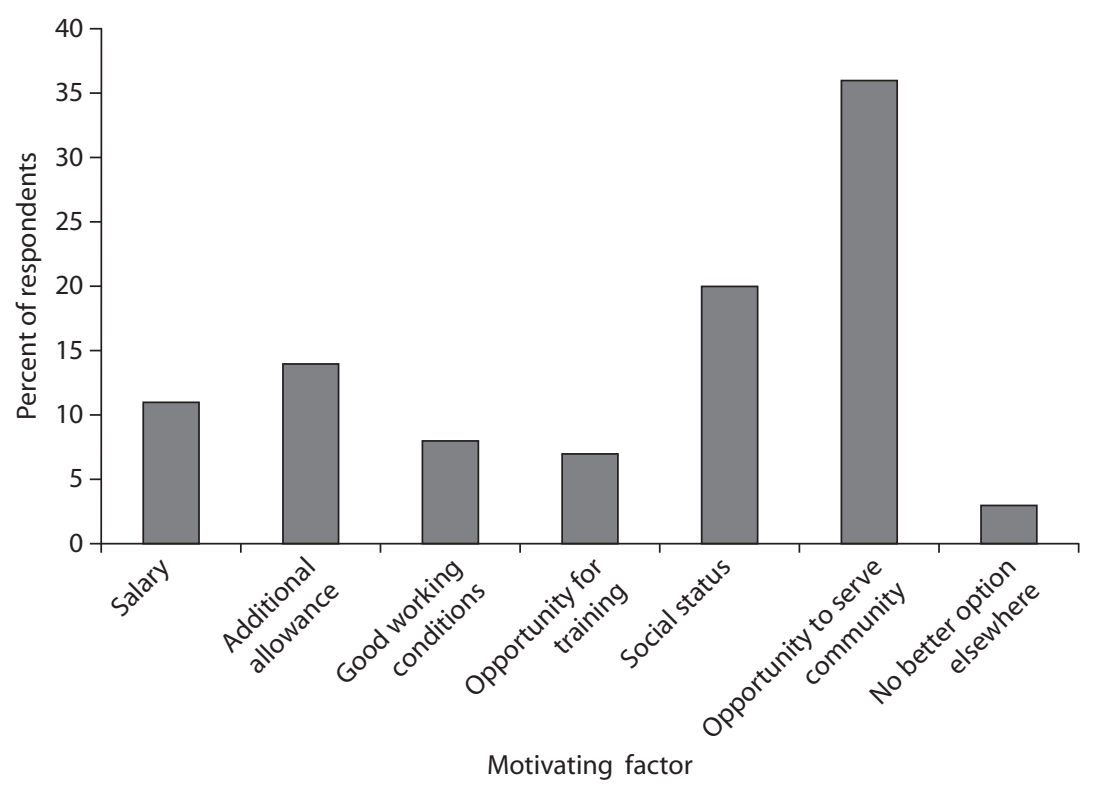

Source: Witter et al. 2006.

Note: Respondents were asked to rank various factors from 0 to 9 . The figure reports the total scores (the sum of all scores divided by the total).

travel to Accra) are demotivating (Rassekh 2008). A 2010 study of a hospital in the Central region found that focusing on good working conditions for staff increased their effectiveness and motivation (Marchal, Dedzo, and Kegels 2010). A comprehensive study will need to be carried out in Ghana to assess current levels of health worker motivation and the different factors that affect it.

\section{Conclusion}

Evidence on the different aspects of health worker performance is sparse. More research is needed on health worker competency and application of effort (and the factors determining these), ideally by level of care, sector, and health worker. Existing studies indicate mixed results, with some of the evidence-particularly on maternal health-suggesting that competencies may not always be as solid as they could be, and that existing working environments sometimes limit the extent to which high-quality 
services can be provided. In addition, although the evidence is not always negative, attention should be paid to remaining levels of absenteeism, variations in health worker responsiveness, and productivity. Addressing performance issues in Ghana will involve drilling down into the key reasons why health worker performance in some regions or districts, in some sectors, or of specific health cadres may not always be as good as it could be. Further assessing and measuring weaknesses in education and training capacity as well as working environments will inform policies to improve competencies and to enhance the ability of health workers to practice what they know. Further understanding not only the limitations, but also the positive experiences that result from stronger management and accountability mechanisms and health worker motivation will help inform the development of interventions to ensure that health workers apply themselves fully and achieve optimal results.

\section{Notes}

1. The 2002 Ghana Service Provision Assessment Survey (GSPAS) was conducted in a representative sample of 428 health facilities throughout Ghana. The survey covered hospitals, polyclinics, health centers, health posts, clinics, and private maternity homes, and included both government (public) and approved nongovernment (private) facilities. The GSPAS used interviews with health service providers and clients as well as observations of providerclient consultations to obtain information on the capacity to provide care and the existence of functioning systems to support quality services.

2. The 2007 Ghana Maternal Health Survey is the first nationally representative, population-based survey to collect information on maternal health and mortality in Ghana through a combination of data collection at the household level and at the individual woman level, and a follow-on verbal autopsy into the specific causes of female deaths, particularly maternal deaths.

3. A partograph is a single-page monitoring tool, developed by the WHO, that allows a trained birth attendant to monitor the progress of labor and will signal when a labor has become complicated.

4. Mystery shopping or a mystery consumer is a tool used externally by market research companies or watchdog organizations, or internally by companies themselves, to measure the quality of service or compliance to regulation, or to gather specific information about products and services. The mystery consumer's specific identity is generally not known by the establishment being evaluated. Mystery shoppers perform specific tasks, such as purchasing a product, asking questions, registering complaints, or behaving in a certain way. They then provide detailed reports or feedback about their experiences. 
5. An equivalent patient day (EPD) combines inpatient days and outpatient visits using a weighting of three outpatient visits to one inpatient day.

6. Productivity was calculated as composite service delivery divided by composite human resources for health. Composite service delivery was calculated by adding all services together, weighted as follows: $(1 \times$ outpatient days; $1 \times$ antenatal care; $0.5 \times$ immunization; $3 \times$ inpatient days; $3 \times$ supervised deliveries). Composite human resources for health were calculated as the total wage bill for clinical and support staff working in the district (excluding national and regional staff, because they cannot be mapped onto any particular district).

\section{References}

Abekah-Nkrumah, G.,A. Manu, and R.Atinga. 2010. "Assessing the Implementation of Ghana's Patient Charter." Health Education 110 (3): 169-85.

Acquah, S., E. Agongo, B. Sarkodie, and A. Fianko. 2008. Achieving Health Results: The Use of District "League Tables" in Eastern Region, Ghana. Unpublished. Accra: Ministry of Health.

Adams, I., D. Darko, and S. Accorsi. 2004. "Malaria: A Burden Explored." Bulletin of Health Information 1 (1): 28-34.

Addai, E., and S. Bosomprah. 2007. "Health Workforce Productivity." Presentation to the Ministry of Health, Accra.

Addo, W. 2009. "Workload Analysis from the Eastern Region." Presentation to Human Resources for Health meeting, Accra.

Agyepong, I. 1999. "Reforming Health Service Delivery at District Level in Ghana: The Perspective of a District Medical Officer." Health Policy and Planning 14 (1): 59-69.

D’Ambruoso, L., M. Abbey, and J. Hussein. 2005. "Please Understand When I Cry Out in Pain: Women's Accounts of Maternity Services during Labour and Delivery in Ghana." BMC Public Health: 5: 140. http://www.ncbi.nlm.nih .gov/entrez/query.fcgi? cmd=.

Ansong-Tornui, J., M. Armar-Klemesu, D. Arhinful, S. Penfold, and J. Hussein. 2007. "Hospital Based Maternity Care in Ghana: Findings of a Maternal Enquiry into Hospital Deaths." Ghana Medical Journal 41 (3): 125-32.

Awases, M., A. Gbary, J. Nyoni, and R. Chatora. 2004. Migration of Health Professionals in Six Countries: A Synthesis Report. Brazzaville: WHO Regional Office for Africa.

Bannerman, C., S. Larbi Wumbee, A. Plange, Y. Brobbey, N. Konadu, M. Osei, W. Asare, C. Boye, and A. Sarpong. 2010. Customer Care Mystery Shopper Report. Accra: Ghana Health Service. http://www.scribd.com/doc/33672041/ Mystery-Shopping-Ghana-Health-Service. 
Beciu, H., A. Preker, S. Ayettey, J. Antwi, A. Lawson, and S. Adjey. 2009. "Scaling Up Education of Health Workers in Ghana." Working Paper, Unpublished, World Bank, Washington, DC.

CSR-Health Ghana (Country Status Report on Health, Ghana). 2011. Ministry of Health, Ghana, and World Bank. Unpublished.

Deganus, S. 2008. “Achieving MDG5: Improving the Quality of Care.” Presentation to the national emergency meeting on maternal health, Accra.

Deganus, S., and J. Tornui. 2006. "Impact of Free Delivery Policy on Utilization and Quality of Care at Level B (Basic Obstetric Care) Facilities in Ghana." Aberdeen and Accra: IMMPACT.

Ferrinho, P., W. Van Lerberghe, I. Fronteira, F. Hipólito, and A. Biscaia. 2004. "Dual Practice in the Health Sector: Review of the Evidence." Human Resources for Health 2: 14. http://www.ncbi.nlm.nih.gov/pmc/articles/PMC529467/.

Franco, L. M., S. Bennett, and R. Kanfer. 2002. "Health Sector Reform and Public Sector Health Worker Motivation: A Conceptual Framework." Social Science and Medicine 54: 1255-66.

Frimpong, J. A., S. Helleringer, J. K. Awoonor-Williams, F. Yeji, and J. F. Phillips. 2011. "Does Supervision Improve Health Worker Productivity? Evidence from the Upper East Region of Ghana." Tropical Medicine and International Health 16 (10): 1225-33. http://www.ncbi.nlm.nih.gov/pubmed/21729221.

GSS (Ghana Statistical Service), GHS (Ghana Health Service), and Macro International. 2009. Ghana Maternal Health Survey 2007. Calverton, Maryland, and Accra: GSS, GHS, and Macro International. http://www .measuredhs.com/pubs/pdf/FR227/FR227.pdf.

GSS (Ghana Statistical Service), Ministry of Health, and ORC Macro. 2003. Ghana Service Provision Assessment Survey 2002 (GSPAS). Calverton, Maryland, and Accra: Ghana Statistical Service and ORC Macro. http://www .measuredhs.com/pubs/pdf/SPA6/00FrontMatter.pdf.

Kraus, R. 1998. Final Report on Optimal District Personnel and Skills Mix: Requirements for Delivery of Primary Health Care Services. Bisho, South Africa: Department of Health, Eastern Cape Province.

Lievens, T., P. Serneel, S. Garabino, P. Quartey, E. Appiah, H. C. Herbst, C. Lemiere, A. Soucat, L. Rose, and K. Saleh. 2011. "Creating Incentives to Work in Ghana: Results from a Qualitative Health Worker Study." Health, Nutrition and Population (HNP) Discussion Paper, November, World Bank, Washington, DC.

Marchal, B., D. Dedzo, and G. Kegels. 2010. "A Realist Evaluation of the Management of a Well Performing Regional Hospital in Ghana." BMC Health Services Research 10: 24. 
Martinez, J., and T. Martineau. 2001. "Introducing Performance Management in National Health Systems: Issues on Policy and Implementation." IHSD Issue Note, Institute for Health Sector Development, London.

Mathauer, I., and I. Imhoff. 2006. "Health Worker Motivation in Africa: The Role of Non-Financial Incentives and Human Resource Management Tools." Healthcare Worker 4 (24). www.human-resources-health.com/content.

Ministry of Health. 2002. An Assessment of the Pharmaceutical Sector in Ghana. Accra: Ministry of Health.

Nyarko P., H. Birungi, M. Klemesu, D. Arhinful, S. Deganus, H. Agyarko, and G. Brew. 2006. Acceptability and Feasibility of Introducing the WHO Focused Antenatal Care Package in Ghana. Washington, DC: Population Council, Frontiers in Reproductive Health. http://www.popcouncil.org/pdfs/frontiers/ FR_FinalReports/ghana_who_anc.pdf.

Quality Health Partners and Ghana Health Service 2005. Facility Baseline Assessment of Regional Hospitals and Facilities in 28 Target Districts in Seven Regions of Ghana. Accra: Quality Health Partners.

Rassekh. 2008. Ministry of Health interview with the Director for HRH, August. Townend, J., G. Martin, S. Deganus, J. Tornui, and C. Ronsmans. 2006. Quality of Clinical Obstetric Care in District and Regional Hospitals in the Central and Volta Regions of Ghana. Aberdeen: IMMPACT.

USA Today. 2010. "As Primary Care Shortage Looms, Doctors Cut Work Hours." Posted February 26. http://www.usatoday.com/news/health/2010-02-26primary-doctors_N.htm.

Vujicic, M., E. Addai, and S. Bosomprah. 2009. "Measuring Health Workforce Productivity: Application of a Simple Methodology in Ghana" Health, Nutrition and Population (HNP) Discussion Paper, August 2009. http://siteresources.worldbank.org/HEALTHNUTRITIONANDPOPULATION/ Resources/281627-1095698140167/MeasuringHlthWorkforce.pdf.

WHO (World Health Organization). 2006. World Health Report 2006: Working Together for Health. Geneva: WHO. www.who.int/whr/2006/en/index.html.

Witter, S., and B. Garshong. 2009. "Something Old or Something New? Social Health Insurance in Ghana." BMC International Health and Human Rights 9: 20. www.biomedcentral.com/1472-698X/9/20.

Witter, S., J. Koot, J. T. Cammack, G. Buckle, and A. Bjerrum. 2009. Pulling Together, Achieving More: Independent Health Sector Review for 2008. Accra: Ministry of Health.

Witter, S., A. Kusi, and M. Aikins. 2007. "Working Practices and Incomes of Health Workers: Evidence from an Evaluation of a Delivery Fee Exemption Scheme in Ghana." Human Resources for Health 5: 2. http://www.human-resourceshealth.com/content/5/1/2. 
Witter, S., A. Kusi, M. Aikins, and D. Arhinful. 2006. Evaluation of the Free Delivery Policy in Ghana: Findings of the Health Worker Incentives Survey. Aberdeen, U.K.: IMMPACT.

World Bank, Ministry of Health, and Ghana Health Service. 2006. Mapping Health Workforce Productivity in Ghana. Accra: Ministry of Health. 